\title{
"Nuestra única venganza es ser felices": emociones, sentimientos y militancias de H.I.J.O.S. en Espacios de memoria
}

\author{
Carolina Sofía Tavano \\ Universidad Nacional de Mar del Plata/CONICET, Mar del Plata, Argentina \\ Email: carolinatavano@conicet.gov.ar
}

\begin{abstract}
Resumen: El presente trabajo se inserta en los debates acerca del lugar que ocupan las emociones y sentimientos en la constitución y permanencia de la acción colectiva, entendiéndolos como resultado de construcciones socioculturales, cuyo abordaje permite comprender de manera más compleja diversos fenómenos sociopolíticos.El objetivo es analizar los sentidos, emociones y sentimientos que se construyen entre los militantes de la agrupación H.I.J.O.S. a partir de la participación en el Espacio de memoria ExESMA, en relación con el propio espacio, la agrupación y sus integrantes, como también hacia las autoridades del Gobierno Nacional entre los años 2003 y 2015. Desde una metodología cualitativa, se priorizará la perspectiva de los actores a partir de testimonios recuperados de fuentes primarias y secundarias.

Mediante el análisis de esta experiencia se dará cuenta de cómo sentimientos como la injusticia, la impunidad y el dolor son procesados y transformados colectivamente a partir de la organización, a la par que se redefine su vinculación con el Estado.
\end{abstract}

Palabras Clave:Hijos de desaparecidos;ESMA;sitios de memoria; estado; kirchnerismo; sociología de las emociones

\section{"Our only revenge is to be happy": emotions, feelings and the H.I.J.O.S. militancy in Spaces of memory}

\begin{abstract}
The present work is inserted in the debates about the place that the emotions and feelings take in the constitution and lastingness of the collective action, understanding them as result of sociocultural constructions, whose approach allows to understand in a more complex way diverse sociopolitical phenomena.The objective is to analyze the senses, emotions and feelings that are constructed between the militants of the group H.I.J.O.S. from the participation in the Memory Space ExESMA, in relation with the own space, the group and its members, as also towards the authorities of the National Government between 2003 and 2015. From a qualitative methodology, the perspective of the actors will be prioritized from testimonies recovered from primary and secondary sources.

Through the analysis of this experience, it will become clear how feelings such as injustice, impunity and pain are collectively processed and transformed from the organization, while at the same time redefining its link with the State.
\end{abstract}

Keywords: Children of disappeared people; ESMA; places of memory; state; kirchnerism; sociology of emotions

\section{“Nossa única vingança é ser feliz": emoções, sentimentos e militâncias de H.I.J.O.S. nos Espaços de memoria}

Resumo: O trabalho apresentado é localizado entre os debates sobre o lugar que têm as emoções, e sentimentos na constituição e permanência da ação coletiva, entendendo-os como resultado de construções socioculturais, cuja abordagem permite compreender de uma maneira complexa diversos fenômenos sócio-políticos.O objetivo é analisar os sentidos, emoções e sentimentos que são construídos entre os militantes do agrupamento H.I.J.O.S. desde a participação no Espaço 
da Memória ExESMA, em relação ao próprio espaço, ao agrupamento e seus membros, bem como às autoridades do Governo Nacional, entre 2003 e 2015. Baseado em uma metodologia qualitativa, vai se priorizar a perspectiva dos atores partindo de depoimentos recuperados de fontes primárias e secundárias.

Através da análise desta experiência, vai se dar conta de como os sentimentos como a injustiça. a impunidade e a dor, são coletivamente processados e transformados desde a organização, enquanto a sua ligação ao Estado é redefinida.

Palavras-chave: Filhos de desaparecidos; ESMA; sítios de memória; estado; kirchnerismo; sociologia das emoções

\section{Introducción}

"No cometimos ni un solo acto de venganza a lo largo de nuestra historia. Nuestra lucha es colectiva y política. Decimos: “nuestra mejor venganza es ser felices” y así construimos nuestra organización (...) proponiendo siempre la celebración de la participación política, renovando la militancia por la Justicia.” (H.I.J.O.S., 2011)

Transformar el dolor y la rabia en felicidad, desafiando a quienes postulan que la movilización de familiares y víctimas del terrorismo de Estado está motivada por la búsqueda de “venganza” (H.I.J.O.S., 2012), se ha convertido en los últimos años en uno de los lemas de la agrupación formada por hijas e hijos de las víctimas del terrorismo de Estado en Argentina: "Hijas e hijos por la Identidad y la Justicia contra el Olvido y el Silencio" (H.I.J.O.S.), representante de una de las más recientes generaciones ${ }^{1}$ incorporadas al movimiento de derechos humanos $(\mathrm{MDH})^{2}$.

A partir del año 2000, el proceso de "recuperación”3 de sitios que habían funcionado como centros clandestinos de detención (CCD) durante la última dictadura militar (1976-1983) para dar lugar a la creación de "Espacios de memoria"4 pasó a ocupar un lugar central en la agenda del MDH, abriendo nuevos canales de diálogo con diferentes actores estatales, lo cual condujo a una progresiva redefinición del vínculo con lo estatal; proceso que se aceleraría con el cambio de ciclo político inaugurado en el año 2003, luego de que Néstor Kirchner asumiera la Presidencia de la Nación.

Con el objetivo de profundizar el conocimiento acerca de estas experiencias de recuperación de sitios y de articulación con el Estado, el presente trabajo propone una aproximación sociológica a la comprensión de los sentidos, sentimientos y emociones ${ }^{5}$ que se produjeron entre las/os militantes de H.I.J.O.S. a partir de su participación en espacios de memoria durante los años de gobiernos nacionales kirchneristas ${ }^{6}$ (2003-2015) y sus transformaciones, indagando cómo esta dimensión de la participación pudo haber incidido, a su vez, en la organización del colectivo, su actividad política en general y sus interpretaciones sobre el Estado y las autoridades del gobierno nacional.

En este sentido, nos preguntamos cómo los sentimientos de injusticia, impunidad y dolor que impregnaron los discursos de H.I.J.O.S. y los testimonios de sus integrantes en sus primeros años de activismo se transformaron, dando lugar a emociones de "resistencia” (Whittier, 2001), como pueden ser la alegría, la esperanza y el orgullo.

Puntualmente, se analizará el caso de la "recuperación” del ex CCD que funcionó en los edificios de la Escuela de Mecánica de la Armada $\left(E^{2} M A^{7}\right)$ que daría lugar a la creación del "Espacio para la Memoria y para la promoción y defensa de los Derechos Humanos (Ex ESMA)”, desde la perspectiva de militantes de la agrupación H.I.J.O.S. Capital (las/os "hijxs" de aquí en adelante), enfocándonos en sus discursos y testimonios en relación con algunos eventos claves de la historia del Espacio (el acto donde se anuncia su "recuperación” en el año 2004; la apertura de la "Casa de la Militancia" -sede de H.I.J.O.S. Capital- en 2011; los conflictos en torno a los “asados" en 2012 y 2013) 
Proponemos abordar esta problemática en torno a dos ejes que no han sido indagados en profundidad en los estudios previos sobre H.I.J.O.S.: por un lado, analizando la participación en espacios de memoria como una dimensión constituyente de su militancia; y por otro, el papel que juegan las emociones en la transformación de sus interpretaciones acerca del Estado en general y el gobierno nacional y las autoridades, en particular.

Se partede un enfoque teórico de la acción colectiva que prioriza el análisis de la vinculación entre política y emociones/sentimientos (Jasper, 2013), entendiéndolos no solo como experiencias individuales/psicológicas sino también como resultado de construcciones socioculturales (Hochschild, 1979; 1983), por lo que a lo largo del artículo se pretenderá analizar la dimensión colectiva de las emociones que se entrelazan con las prácticas y discursos de los actores, considerando el análisis de esta dimensión no solo como complementaria para el estudio de movimientos sociales, sino también asumiendo que permite explicar una parte constituyente de los mismos y la continuidad de su activismo (Poma y Gravante, 2015).

A diferencia de algunas lecturas que interpretan a la vinculación entre el MDH y el Estado o los gobiernos en términos clientelares, motivada por pura conveniencia política/económica o como una "cooptación" (Svampa, 2018) y específicamente a H.I.J.O.S. (Di Marco, 2012; Gasulla, 2012) reduciendo en algunos casos la acción política a una simple estrategia calculada de "maximización de recursos" o, en otros casos, considerando a los actores como sujetos pasivos frente a la estructura estatal (Alonso, 2009), intentaremos demostrar que es posible comprender esta vinculación de una forma más compleja, observando cómo se ponen en juego diferentes elementos objetivos y subjetivos que no siempre responden a una estrategia lineal y calculada, pero que suponen un rol activo de quienes llevan adelante estos emprendimientos.

En línea con las teorías que enmarcan este trabajo, el abordaje metodológico es cualitativo, otorgándole un lugar privilegiado a la perspectiva de los actores, aunque también se consultarán diversas fuentes para reponer miradas externas y elementos contextuales. Por un lado, se analizarán testimonios de militantes de H.I.J.O.S. Capital que participaron bajo diferentes modalidades en el Espacio ExESMA (en la discusión de los proyectos de creación, en espacios de gestión más o menos institucionalizados, en el desarrollo de actividades militantes y/o laborales en el marco de este espacio) y que son al mismo tiempo familiares directas/os de las víctimas $^{8}$; testimonios obtenidos de entrevistas realizadas en el marco de esta investigación (que se citarán indistintamente como "Militante de H.I.J.O.S.”, en tanto la identificación de los entrevistados no resulta relevante para los objetivos de este trabajo) y otros, de fuentes secundarias, referenciadas en el apartado de Bibliografía (que se citarán como Militante de H.I.J.O.S., 2013 y 2015). Por otra parte, se complementará con el análisis de documentos públicos de la organización, archivo periodístico y revisión bibliográfica de antecedentes sobre la temática estudiada.

\section{La articulación entre política y emociones para pensar el vínculo entre acción colectiva y Estado}

Durante las últimas dos décadas, la sociología estadounidense y europea ha recuperado el análisis de los sentimientos y emociones como dimensión de análisis fundamental para comprender el surgimiento, sostenimiento y desarticulación de la acción colectiva y los movimientos sociales. Esta línea teórica que articula política y emociones tiene como uno de sus antecedentes principales los trabajos de Ana Hochschild (1979, 1983), quien destacó la importancia de las emociones para el abordaje complejo de problemas sociales de diversa índole, analizando cómo la codificación y expresión (o supresión) de emociones se encuentra sujeta a determinadas "reglas del sentir", que pueden ser manejadas/trabajadas de forma individual o colectiva.

Estos aportes fueron luego trasladados al campo de la política, recuperándose desde finales de los noventa, por los teóricos de la acción colectiva (Della Porta, 1995;Goodwin, Jasper y Polletta, 2001; Adams, 2003; Jasper, 2012; 2013) para pensar la protesta y los movimientos sociales, discutiendo principalmente con los enfoques "racionalistas" que explicaban la acción colectiva como acciones meramente instrumentales, calculadas, motivadas por la búsqueda de retribuciones (Olson, 1965). 
Desde una perspectiva con pretensión de síntesis entre los análisis más estructurales y aquellos que, por el contrario, se centraban en la capacidad cognitiva/racional de los individuos que participaban en la acción colectiva, McAdam, McCarthy y Zald propusieron recuperar la noción de "procesos enmarcadores” (Gamson y Meyer, 1996) para reponer la instancia mediadora entre oportunidad política, organización y acción, es decir, la organización de: "los significados compartidos y conceptos por medio de los cuales la gente tiende a definir su situación”(1996, p. 26). Desde esta perspectiva, los significados compartidos y los esquemas de percepción e interpretación (que, a su vez, están mediados por las emociones -Flam, 2005-) constituyen un factor igualmente constitutivo para habilitar la existencia de movimientos sociales y el desarrollo de la acción colectiva.

A su vez, existen investigaciones que han mostrado la utilidad de estas teorías para pensar la relación entre los movimientos sociales y el Estado, el gobierno y sus autoridades (Della Porta, 1995; Whittier, 2001; Flam, 2005; Romanos, 2011; 2014). Nos interesa destacar, en particular, el trabajo de Flam (2005), quien construye una agenda de investigación en la temática enfocándose en estudios que muestran cómo determinadas emociones se encuentran en la base de las acciones de los movimientos sociales, quienes desafían las "reglas del sentir" dominantes cuando, por ejemplo, siembran la desconfianza hacia el Estado, se reapropian de la capacidad de sentir enojo (emoción legitimada para los grupos dominantes) o ponen en marcha procesos de desafecto y transferencia de lealtades a partir de cierta "liberación emocional". Al remarcar sobre todo los procesos de de-construcción o re-direccionamiento de emociones por parte de los movimientos (siendo algunas de estas las que sedimentan las estructuras sociales y las relaciones de dominación), la autora destaca cómo las emociones ponen en relación los procesos macro-políticos con los micro-políticos.

En cuanto a los estudios de caso, la investigación de Whittier (2001) acerca del movimiento contra el abuso sexual infantil en Estados Unidos, nos resulta un aporte significativo a la hora de pensar cómo se manifiestan las emociones en los discursos de las organizaciones sociales y sus integrantes de acuerdo con los diferentes contextos (al interior del movimiento, en contextos públicos y/o teniendo al Estado como principal interlocutor), las cuales están sujetas a diferentes tipos de manejo emocional para lograr cierta adecuación. Whittier muestra también cómo los contextos se articulan, al señalar que "las dinámicas y discusiones internas del movimiento, es decir, los procesos emocionales interpretativos colectivos, moldean tanto la reconstrucción de las emociones dentro de los escenarios del movimiento como su presentación pública” (2001, p. 249 traducción propia-).

Por último, consideramos productiva la distinción que hace la autora entre emociones de trauma y las de resistencia; recuperadas, a su vez, en el trabajo de Poma y Gravante (2019) para analizar cómo las emociones se articulan en torno a (y construyen interpretativamente) determinados acontecimientos, definidos en clave de "trauma cultural". Otro antecedentes importante constituyen la investigaciones de Romanos sobre el anarquismo durante el franquismo español, dando cuenta de cómo los factores emocionales, identitarios y los marcos estratégicos permitieron sostener el activismo en contextos represivos, a la vez que fomentaron que se intensifique la movilización a raíz de la configuración de "energías emocionales” positivas, de esperanza, que favorecieron la interpretación de determinados procesos políticos en clave de oportunidades durante los últimos años del franquismo (2011),realizando, a su vez, un análisis longitudinal de las prácticas emocionales y su evocación, aprehendiendo sus variaciones a partir del trabajo emocional (2014).

Este abordaje ha comenzado a ser adoptado sobre todo durante la última década, para pensar las experiencias latinoamericanas, en particular los casos de protesta y movimientos sociales en contextos represivos, destacándose la investigación de Wood (2001)para el caso del activismo campesino en El Salvador, donde analizó la importancia de los "beneficios emocionales" de la participación para sostener el activismo. Bayard de Volo (2006) también analizó este aspecto, a partir del caso de una organización de madres de víctimas en Nicaragua, observando la articulación entre emociones, identidad colectiva y género. Adams (2003) observando un caso activistas mujeres en Chile, se centró en analizar cómo las emociones pueden sostener el movimiento en contextos represivos y cómo se transforman ante la disolución del mismo.

Sobre el activismo de alto riesgo en Colombia, aportan valiosas reflexiones los trabajos de Bolivar (2006), quien se focalizó en el análisis de los “discursos emocionales” en intersección con los lenguajes políticos y de Otero Bahamón (2006), quien exploró las motivaciones individuales y las emociones que surgen a 
partir de las relaciones sociales en organizaciones armadas, explicando los motivos de ingreso y permanencia en las mismas. Por último, son antecedentes fundamentales los trabajos de Poma y Gravante (2015, 2018a, 2018b, 2019), quienes a partir del estudio de diversos casos de activismo político en México, han actualizado y profundizado varias de las aristas de análisis que comprenden al enfoque teórico presentado, enfatizando la importancia del trabajo emocional como práctica política.

Si bien para el análisis de las experiencias locales (en Argentina) existen algunos trabajos que han abordado la vinculación entre movimientos sociales y Estado desde la sociología política, se encuentran muy pocos trabajos que hayan optado por este enfoque teórico, dejando el análisis de la articulación entre política y emociones en un segundo plano. En relación con el caso que nos ocupa específicamente, existen algunas excepciones, como son las investigaciones de Jelin (2003;2007;2017) y Andriotti Romanin (2012; 2014; 2015), que han incorporado esta dimensión de análisis a la hora de problematizar la vinculación entre organizaciones de familiares o "afectados directos" del MDH y el Estado; mientras que Jelin analizó el fenómeno del "familismo" a raíz de la importancia que cobraron las organizaciones de familiares en el espacio público, logrando legitimarse como actores políticos a partir de su vínculo familiar mediante la evocación de factores emocionales y afectivos (2007); Andriotti Romanin (2012, 2014) exploró la creciente articulación política entre una de las organizaciones de madres y el Estado, a partir de su afinidad ideológica y la construcción discursiva de un lazo afectivo con las autoridades.

Desde una perspectiva antropológica, también cabe destacar los estudios sobre el activismo de organizaciones de "víctimas": Vecchioli $(2001,2005)$ analizó a partir del caso del MDH la construcción de la categoría de "víctima” y la legitimidad política a partir de su relación con el Estado, mientras que Zenobi (2014) exploró diferentes prácticas de trabajo emocional entre las organizaciones de familiares de las víctimas de Cromañón, reponiendo también los vínculos que se fueron estableciendo con diferentes actores y agencias estatales.

Aunque en las investigaciones sobre el caso de H.I.J.O.S. la dimensión emocional y afectiva ocupó un lugar central, en particular entre los trabajos que se han focalizado en el estudio de la identidad colectiva de las/ os hijxs (Bonaldi, 2006; Cueto Rúa, 2010a; 2010b), no se ha indagado en cómo las emociones producidas y/o manejadas colectivamente pudieron incidir en sus maneras de interpretar y vincularse con el Estado a lo largo de su trayectoria; constituyendo uno de los ejes centrales del presente trabajo, con el que se espera poder contribuir a los debates de este incipiente campo de estudios en Argentina.

\section{La "recuperación de la ex ESMA: emociones encontradas. De la impunidad a la desconfianza}

Desde su surgimiento a mediados de la década de 1990, la agrupación H.I.J.O.S. cobró gran protagonismo en la escena política local, incorporándose a la lucha histórica del MDH por las demandas de memoria, verdad y justicia en relación con los crímenes cometidos durante la última dictadura militar en Argentina (1976-1983), pero también destacándose junto con otras organizaciones sociales y políticas que ocuparon las calles con movilizaciones y protestas durante aquellos años, articulando sus diversas demandas en el marco de las luchas contra las políticas neoliberales en la Argentina. (Bonaldi, 2006; Jelin, 2007). En sintonía con el resto del MDH, en el comienzo de la agrupación el Estado se constituyó como el principal interlocutor, estructurando su acción política en torno a las demandas centrales de "Juicio y Castigo" a los responsables de los crímenes cometidos durante el terrorismo de Estado (Alonso, 2016; Cueto Rua, 2016a).

Más allá del marco compartido por la mayoría de las organizaciones del MDH en su forma de concebir y relacionarse con el Estado durante este período, las distintas organizaciones presentaron divergencias políticas y estratégicas, de modo que la gran mayoría de las iniciativas y proyectos que emprendieron colectivamente no estuvieron exentos de controversias y debates a la hora de su diseño y ejecución (Jelin, 2017). En este sentido, qué hacer con los sitios que habían funcionado como CCD no fue la excepción, constituyendo uno de los grandes temas a discutir entre las organizaciones del MDH (Vezzetti, 2009; Jelin, 2017; Guglielmucci, 2011; Da Silva Catela, 2014; Messina, 2016; Feld, 2017). 
A pesar de la existencia de algunas resistencias que en un principio generaba en las/os hijxs involucrarse en los proyectos sobre sitios de memoria y entablar, al mismo tiempo, un diálogo con el "Estado", a medida que los emprendimientos se fueron multiplicando, en algunos casos por inquietudes personales y luego por decisiones colectivas, comenzaron a tomar protagonismo en los diferentes espacios (más o menos institucionalizados) para pensar las características de los proyectos, gestionar su funcionamiento y darles “contenido”. (Guglielmucci, 2011; Messina, 2015; Cueto Rúa, 2016b)

Estos debates se vieron acelerados a partir del caso de la exESMA. El 24 de marzo de 2004 (fecha en que se conmemora el golpe de Estado que daba inicio en 1976 a la dictadura cívico-militar más violenta de la historia argentina), el presidente Néstor Kirchner, a menos de un año de haber iniciado su mandato, encabezó un acto oficial con motivo de la firma del convenio conjunto con el Gobierno de la Ciudad Autónoma de Buenos Aires (CABA) para la creación de un Museo de la Memoria y para la Promoción y defensa de los Derechos Humanos en ese mismo espacio. Este acto inauguró el proceso conducente a la creación del Ente público "Espacio para la Memoria y para la promoción y defensa de Derechos Humanos" en la ExESMA, constituyendo una de las políticas públicas de memoria de mayor visibilidad durante el período que el kirchnerismo estuvo al frente del Poder Ejecutivo Nacional (P.E.N.). Su importancia radica no sólo en la reconversión de aquel lugar emblemático (ícono del terrorismo de Estado en la Argentina) en un espacio que pasaba a proponerse "como un ámbito de homenaje a las víctimas y de condena a los crímenes de lesa humanidad cometidos durante el terrorismo de Estado" y "de referencia nacional e internacional de políticas públicas de memoria, de

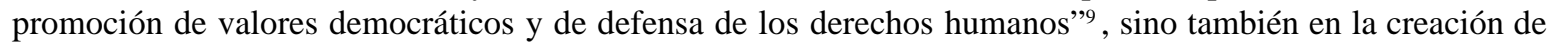
nuevos programas, instituciones y organismos estatales específicos, la relocalización de otros ya existentes en ese predio y la consecuente inversión presupuestaria que conllevó su creación y mantenimiento.

Las acciones que tuvieron lugar ese 24 de marzo configuraron un hecho político clave, reconocido por muchos de los integrantes de las organizaciones que conforman el MDH como un momento fundante de la nueva relación que se comenzaría a configurar con el Estado. Algunas/os hijxs recordarán este acto como el momento donde el Estado le "entregó" la ESMA a los familiares, inaugurando un proceso de transformación en la relación con el Gobierno, que llevaría algunos años y numerosos debates internos y repercusiones al interior de la agrupación. Una clara expresión de este momento de "quiebre" se desprende del testimonio de un hijx, que recuerda su participación en aquel acto y relata la vacilación entre entrar o no al predio junto con otras organizaciones de familiares:

"El día que Néstor nos entrega la ESMA (a nosotros y al pueblo argentino), nosotros no queríamos entrar al lugar. (...) Habíamos decidido no entrar y todos los organismos habían decidido no entrar, por lo que significaba. (...) Ese día nosotros tuvimos una reunión hasta muy tarde y terminamos decidiendo que queríamos hablar. Ese día dimos un discurso muy duro... que no era contra Néstor, era contra el Estado; queríamos escupir un montón de cosas que teníamos para decir (...). Y después, decidimos entrar. (...) Fue un día histórico.” (Militante de H.I.J.O.S., 2018)

Esa "desconfianza” originaria hacia la gestión de Kirchner (fundada en gran parte en la histórica relación del MDH con el Estado y las sucesivas gestiones, construida sobre un marco interpretativo de impunidad -Andriotti Romanin, 2012) se ve plasmada en el documento leído por H.I.J.O.S. ${ }^{10}$ en aquel acto oficial (que se realizó fuera del predio), a través del cual se enumeraron una serie de demandas hacia el Estado, al mismo tiempo que se definía el motivo de su presencia en la ex ESMA:

"Porque nosotros hoy, acá, hemos venido a hacer lo mismo de siempre. Hemos venido a luchar contra la impunidad, contra el olvido, contra el silencio. No hemos venido a la entrega de un predio, aunque la entrega de este predio nos da más fuerza para seguir, como nos dio fuerza la nulidad de las leyes de impunidad en el congreso. No hemos venido a recibir ningún reconocimiento. Porque reconocer nuestra lucha, la de las Madres, la de las Abuelas, la de los Familiares, la de los Ex detenidos no es otra cosa que meter presos a los culpables, recuperar la identidad de todos los jóvenes apropiados durante la dictadura, que nos entreguen toda la verdad sobre nuestros seres queridos y que el proyecto de país por el que luchaban nuestros padres y nuestras madres se convierta en realidad.” (H.I.J.O.S., 2004) 
El documento leído hacía énfasis en lo insuficiente de esta medida, que formaba parte de una de las tantas demandas que se planteaban desde las organizaciones de familiares. Al mismo tiempo, en este fragmento del discurso podemos identificar varios elementos que constituyen los puntos básicos de H.I.J.O.S. y que permiten comprender parte de los motivos de su lucha: por un lado, la presentación de su activismo en el marco de la lucha contra la "impunidad", asociado al sentimiento de injusticia que provocaron principalmente las políticas del alfonsinismo y menemismo entendidas como negacionistas (como las Leyes de Obediencia debida y Punto Final o los indultos a los jefes de las juntas militares ${ }^{11}$ ). En segundo lugar, la referencia a sus "seres queridos”, las víctimas de la represión estatal, a quienes se señala como el motivo central de su lucha, evocándolos con un lenguaje afectivo que sugiere los sentimientos de amor y orgullo por sus "luchas" en la base de sus motivaciones políticas (aspecto que desarrollaremos más adelante).

Uno de los hijxs, recuerda el posicionamiento de la organización ante estos primeros "gestos” políticos del gobierno y su propia intervención en una reunión con el por entonces Presidente Kirchner, al poco tiempo del acto en la exESMA:

"Nosotros habíamos estado totalmente enfrentados al Estado, más que nada por el marco de impunidad, entre otras cosas... Néstor nos convoca, al principio con muchas dudas, con mucha desconfianza (...) y mis palabras en ese acto son de agradecimiento, porque habían entregado la ESMA, habían entregado el "Olimpo"... pero dije: bueno, hay 460 centros clandestinos declarados... ahora vamos por "Campo de Mayo". Entonces tenía que ver con eso: -gracias, pero vamos por todo. No fue una definición de acompañamiento al gobierno...” (Militante de H.I.J.O.S., 2018)

En síntesis, en estas primeras aproximaciones de la organización con el nuevo gobierno, se evidenciaba la intención de marcar una distancia y una diferencia, comenzando a abandonar la interpretación del proceso político en clave de "impunidad" para dar lugar a un período organizado en torno al sentimiento de "desconfianza”, que se traduciría en la continuidad de ciertas acciones propias del repertorio de H.I.J.O.S. (las participación en protestas contra algunas de las medidas del gobierno, la organización de "escraches" a represores ante la ausencia todavía de juicios contra crímenes de lesa humanidad) y la demanda de profundización de algunas de las políticas públicas de memoria que comenzaban a desarrollarse.

\section{Entre el dolor y el orgullo}

Otro de los factores que motivó cierta vacilación entre las organizaciones a la hora de resolver qué hacer ante aquel acto oficial de conmemoración (entrar o no entrar al predio, dar un discurso o no darlo) se vincula con las diferentes emociones que el propio sitio movilizaba en los familiares, amiga/os, compañeros/as de militancia de las víctimas o los propios sobrevivientes. En particular, para quienes tenían conocimiento de que sus seres queridos habían estado secuestrados en la ESMA, el ingreso al predio representaba un desafío, implicando enfrentarse nuevamente con la idea de la muerte y los tormentos que tuvieron lugar mientras funcionaba allí el CCD, actualizando en cierta medida el dolor provocado por la pérdida de familiares, amigos, compañeros y la violencia que debieron atravesar durante el terrorismo de Estado.

Sin embargo, para otros (sobre todo para muchas/os "hijxs") entrar al predio implicaba un acto de homenaje, una demostración de "orgullo" por quiénes fueron sus familiares y, a la vez, una forma de conectarse con ellos ("estar donde ellos estuvieron"), disputando ese espacio a quienes se identificaba como los responsables de las desapariciones y asesinatos (en tanto que aún funcionaban algunas instituciones de la Armada en el lugar). Estas emociones encontradas, se traducían en diferentes posturas acerca de qué acción tomar frente al acto, a nivel individual pero también entre las organizaciones, que debían lidiar con la heterogeneidad de posturas individuales y resolver una dirección política lo más consensuada posible.

Estos debates también se dieron al interior de H.I.J.O.S., quienes tuvieron una serie de reuniones e intercambios previos al acto intentando alcanzar una postura consensuada sobre su participación o no en el mismo, donde se pusieron en común interpretaciones políticas sobre lo que implicaba participar del acto o no hacerlo, como también lo que las/os diferentes hijxs sentían con respecto a ingresar al predio. Así lo recuerda uno de los militantes que participó en las discusiones previas al acto: 
"No había un consenso político, de por qué ir al acto... sino que, para mí, primaron más algunas cuestiones personales; por ejemplo, mi caso, yo decía: -miren, ahí estuvo mi viejo, yo quiero ir, si van a abrir las puertas, tengo que entrar-. Entonces ... algunos compañeros que no estaban dispuestos a ir, que les parecía que... era un error político, por decirlo de alguna manera, terminaron diciendo: -bueno, pero no, pará, si para vos es importante que vayamos, tenemos que estar.” (Militante de H.I.J.O.S., 2018)

Por no alcanzar un acuerdo común al respecto, se resolvió que cada militante decidiría si entraba o no; sin embargo, el día del acto los acontecimientos llevaron a que quienes aún no estaban convencidos terminaran entrando, "llevados" por la energía del colectivo. Algunos entrevistados, relatan que la importancia de los vínculos terminó de "empujar” a quienes originalmente habían decidido no entrar, a hacerlo, ya sea por acompañar a otras/os compañeras/os de H.I.J.O.S. que consideraban importante estar ahí, como a las "madres” y “abuelas” que también terminaron entrando, considerando en algunos casos que tenían el "deber” de acompañarlas y contenerlas, sobreponiéndose a sus propias resistencias.

\section{Lo reparatorio}

En el discurso leído en aquel acto, la/os hijxs analizan la "entrega del predio" como una conquista que les da "más fuerza para seguir", en conjunto con otras políticas recientemente concretadas, como la nulidad de las "leyes de impunidad".

Este efecto de las políticas en clave de incentivo y motivación para la lucha (que, por ese entonces, no implicaba una retribución material sino simbólica y política), se asocian con otro sentimiento que atraviesa a las políticas de memoria en general y es la intención "reparatoria” que subyace a las mismas. Aunque formalmente las políticas reparatorias comprenden "distintas decisiones y acciones tomadas por regímenes políticos para contrarrestar las consecuencias de los crímenes cometidos por regímenes políticos que los antecedieron” (Elster en Andriotti Romanin, 2015:138), el carácter efectivamente "reparatorio" a nivel subjetivo, emocional, en sus destinatarios ha sido y sigue siendo objeto de debates entre los actores. Si bien excede los objetivos de este trabajo la presentación de todos los posicionamientos e interpretaciones sobre este tema, nos interesa mostrar que gran parte de las/os “hijxs” recupera esta política en términos de "reparación”: no solo por sus implicancias a nivel personal (una interpretación que está presente en todas las entrevistas realizadas) sino fundamentalmente en clave de reparación histórica y reconocimiento político, en el marco de una política integral de derechos humanos impulsada desde los gobiernos kirchneristas que darían cuenta de un respaldo y acompañamiento por parte del Estado.

"La política reparatoria es una forma de reconocimiento de terrorismo de Estado. Porque el Estado al reparar, está reconociendo que cometió un delito. (...) Las políticas reparatorias son necesarias, pero no basta con eso... en los noventa, si bien se impulsaron (...) la realidad es que también vienen de la mano de un manto de impunidad: o sea, es decir: "bueno, te pago, callate la boca, ya está, ya está todo". Entonces, no. Es: te pago, hacemos el juicio, recuperamos los sitios, recuperamos a nuestros hermanos, los cuerpos...o sea, esa es la política integral de derechos humanos que comienza con Néstor Kirchner y con Cristina.” (Militante de H.I.J.O.S., 2018)

Es decir, para que la política sea verdaderamente "reparatoria” no alcanzaría con políticas aisladas y puntuales, orientadas a destinatarios individuales (como han sido las leyes de reparación económica ${ }^{12}$ ), sino que deberían darse en el marco de una política integral tendiente a reparar a la sociedad en su conjunto, que manifiesten un compromiso con su causa a largo plazo.

A pesar de la importancia histórica que tendría este acto para las/os "hijxs" (sobre todo reconocida en retrospectiva), los marcos interpretativos sobre el Estado y el gobierno de turno en aquellos primeros años de la gestión de Kirchner se irían transformando muy lentamente, abriendo un período de transición al interior de H.I.J.O.S., marcado por numerosos debates internos, cambios en su conformación y funcionamiento, hasta alcanzar un consenso sobre cómo caracterizar al Gobierno Nacional y definir su propio posicionamiento político. 
“Fue un momento fundacional en el cambio de nuestra relación con el Estado, pero aún así tardamos más en entrar en confianza. H.I.J.O.S. es una agrupación que decide todo por método asambleario, horizontal y hay algunos compañeros que estaban más decididos y otros no tanto. Entonces, se esperaron los tiempos (...) De no estar apoyando a ningún gobierno, se llega a apoyar un gobierno, incluso pidiendo que se lo vote, entonces eso es un cambio que se dio con el tiempo. (...) éramos más anárquicos, no habíamos pensado en esa relación.” (Militante de H.I.J.O.S., 2018)

\title{
“Donde hubo muerte, hoy hay vida": la ocupación de la exESMA como resistencia al terror
}

\author{
Un espacio de esperanza y alegría
}

El 27 de junio de 2011, con una amplia convocatoria de organizaciones sociales, sindicatos, agrupaciones y partidos políticos, organizaciones de derechos humanos y representantes de diferentes áreas de gobierno, H.I.J.O.S. inauguraba su “Casa de la Militancia” en el Espacio ExESMA: el pabellón delta, que les había sido asignado por la Ley Nacional 26.415 en el año 2007, había permanecido desde la recuperación efectiva del predio utilizado con diferentes fines (como sede del Ente Público, espacio para actividades culturales, actos de diferentes organismos estatales, entre otros) en parte por la indefinición de H.I.J.O.S. acerca de qué hacer con ese edificio.

Como mostrábamos en el apartado anterior, los espacios que funcionaron como CCD generaban sentimientos contrapuestos entre los militantes de H.I.J.O.S., en relación con su intervención y presencia en los mismos. Sin embargo, a partir del avance de diversos proyectos de espacios de memoria a lo largo del país y, en particular, el que se estaba desarrollando en la ex ESMA, comenzó a ponerse en juego una resignificación de los espacios, al concebirlos como espacios de promoción y defensa de los derechos humanos, donde al mismo tiempo se promovía la memoria sobre lo ocurrido durante la última dictadura militar, pero no solo como un recordatorio del terror y de aquello que no debería ocurrir "nunca más”, sino también de las luchas y las militancias de la generación de los setenta. Una hijx, recuerda en relación con esto las incomodidades que generaba el espacio en un primer momento y cómo sus percepciones se fueron transformando:

"Es algo tan inmenso la recuperación de la ESMA que lo fui entendiendo y dimensionando a lo largo del tiempo. (...) Ese día, vivimos un momento muy emotivo e inconmensurable. Lo fuerte de entrar a lo que había sido el campo de concentración más grande de la Argentina, era muy impresionante. Y a lo largo del tiempo fuimos cambiando la percepción en relación a ese espacio. Cuando nos citan para decir que teníamos un edificio nos preguntamos si lo queríamos, o no lo queríamos, y para qué lo queríamos. Nos preguntábamos: ¿Fue todo un campo de concentración, o sólo fue el Casino de Oficiales? Fueron un montón de preguntas que uno se iba haciendo, y que se iban contestando con la práctica.” (Militante de H.I.J.O.S., 2013)

A medida que el Espacio ExESMA cobraba vitalidad, las/os "hijxs” comenzaron a involucrarse en diversas actividades y funciones vinculadas a la gestión del Espacio, como también en el diseño y organización de diferentes proyectos que comenzarían a desarrollarse en el predio. De acuerdo con la interpretación de uno de los entrevistados, los diferentes compromisos laborales y de gestión política que algunas/os “hijxs” comenzaron a tomar en las diferentes áreas que funcionaban en el Espacio ExESMA ${ }^{13}$ propiciaron un proceso espiralado de compromiso que a la vez los llevó a tomar conciencia del lugar que tenían en el Espacio ExESMA como organización, motivando la planificación de su “Casa de la Militancia”.

“Cuando estamos ahí, cuando nos toca co-dirigir eso, es que quizás asumimos otro rol en el lugar y empezamos a pensar un proyecto (...). Ahí empezamos a pensar y hacernos cargo de que teníamos la ESMA, que había que gestionarla, que nosotros éramos parte de la gestión y encima de todo, teníamos un edificio. Entonces ahí empieza a cambiar todo un poco (...) porque muchos compañeros trabajaban en dependencias del Estado que empiezan a mudarse a la ESMA. Entonces empieza a cambiar un poco la cabeza de todos. Una cosa es verlo de afuera, otra cosa es transitarlo todos los días... y ahí es 
que empezamos realmente a pensar en el proyecto de la Casa de la Militancia.” (Militante de H.I.J.O.S., 2018)

Cuando el entrevistado dice: “empieza a cambiar un poco la cabeza de todos”, da cuenta de transformaciones que exceden lo racional, lo estratégico en términos políticos: cambia la manera de mirar y de sentir también. El "Estado" dejaba paulatinamente de ser un "enemigo", el "estado genocida" y garante de "impunidad”, pasando a sentirlo como algo propio, como un aliado, un espacio donde tenían una función de "codirección”. Esto implica en muchos de ellos una redefinición que moviliza sentimientos arraigados y los habilitaría a comenzar a pensar su propio lugar en el Espacio ExESMA.

"Este fue un lugar de dolor, de tristeza y de muerte. Ahora, con este acto, estamos inaugurando la Casa de la Militancia, para que este sea un espacio de esperanza, construcción, vida y futuro. (...) Queremos que este lugar sea de todos, queremos llenarlo de política, debate, que se honre permanentemente a LA MILITANCIA, al compromiso, a la solidaridad, al sacrificio, a la alegría y a la organización.” (H.I.J.O.S., 2011)

A través de este discurso, H.I.J.O.S. inauguraba su sede en la Espacio ExESMA, que no era solo una sede de la agrupación, sino más bien un lugar abierto a la militancia toda, como una manera de "honrar" a quienes se sacrificaron en el pasado, pasando a ser un espacio de "esperanza” y “alegría”. La transformación de los sentidos y emociones orientados al propio Espacio, que recuperando los términos de Whitthier (2001) pueden diferenciarse entre emociones del trauma (asociadas al dolor, la tristeza que se vinculan con los acontecimientos del terrorismo de Estado), para luego dar lugar a las emociones de resistencia (como esperanza y alegría), como resultado de un manejo colectivo de las emociones, puede pensarse a partir de al menos dos estrategias: una interna, que expresaría el trabajo del colectivo por dejar atrás las emociones del trauma, para favorecer y estimular la participación de las/os hijxs, sostener la organización evitando asociar el lugar donde algunas/os trabajan, militan y realizan actividades cotidianamente con emociones negativas.

Y en segundo lugar, una estrategia orientada a actores externos(como pueden ser otras organizaciones del MDH y diferentes actores políticos y sociales) ante quienes podrían sentir la obligación de justificarse y defenderse, frente a acusaciones que se condensan en: por un lado, la imputación de sentimientos "revanchistas" y la búsqueda de "venganza" como principal motivación de su acción política. En este sentido, las/os hijxs recurren en sus discursos a la evocación de emociones "positivas” (como el amor, la alegría, la solidaridad) para definir su militancia, contrarios al odio que se supone deberían sentir:

"Le demostramos al mundo que después de tanto horror, de tanta tristeza, tortura y muerte, todo eso se puede transformar en vida. Este Espacio muestra que todos apostamos a la vida, nunca a la muerte y esa apuesta la hacemos con alegría.” (Militante de H.I.J.O.S., 2015)

Y por otro, las acusaciones recibidas en torno a la utilización del Espacio para actividades que fueron catalogadas como inadecuadas o incluso ofensivas. Un ejemplo de esto, constituyen una serie de acusaciones públicas y críticas orientadas a H.I.J.O.S. que llegaron a los medios masivos de comunicación entre finales del año 2012 y 2013 (Etchenique, 2013;Infobae, 2013; Rio Negro,2013), a raíz de la realización de una comida de fin de año en la "Casa de la Militancia" y luego un "asado" (considerado particularmente como ofensivo y de mal gusto, por asociarse con uno de los métodos de tortura utilizado por los represores en el proceso dictatorial). Ante estos hechos, varias/os hijxs salieron públicamente a defender su posición sobre el conjunto de actividades que se estaban desarrollando en la ExESMA, haciendo explícita la resignificación del lugar:

"Desde H.I.J.O.S estamos convencido que hay que hacer asados en la ESMA, y hay que llenarlo de vida al predio, que hay que vivir sin culpa, y que la alegría hace a la militancia, hace al amor al prójimo. Es un debate con los ex Detenidos y con las Madres. A la vez, es un debate que nos encuentra a todos en un lugar diferente, desde el lugar que nos ha tocado vivir a cada uno. Y esos debates están presentes, y seguirán presentes una década más, por lo menos.” (Militante de H.I.J.O.S., 2015) 


\section{Lealtades afectivas}

Siguiendo con el análisis del documento leído durante la inauguración de la "Casa de la Militancia”, otro de los elementos que se destaca es la apelación a un "nosotros" que pretende, con su evocación, delimitar una comunidad, fundada en la militancia como identificación común e invitando a formar parte del espacio a quienes compartan el mismo sentimiento de "justicia”.

"Queremos darles la bienvenida a esta Casa, que partir de este momento es NUESTRA, y cuando decimos "nuestra" nos referimos a que es de todos, de cada organización que emprenda una lucha justa, de cada compañero y compañera que abrace la militancia.” (H.I.J.O.S., 2011)

Este sentimiento de "justicia” se vincula directamente con la interpretación del ciclo político inaugurado por el gobierno de Néstor Kirchner como un proceso donde las demandas del MDH fueron finalmente escuchadas, donde las/os "hijxs" pudieron ser parte de ese proceso, pudiendo avanzar "de la resistencia a la victoria":

“... vemos el proceso político que se abrió el 25 de mayo de 2003. Ahí estamos los H.I.J.O.S. construyendo en lugares como éste sitios para la memoria, para la memoria viva, que construye un futuro mejor. Nosotros cantábamos "los que cayeron son nuestra memoria, de la resistencia a la victoria". Ahora es el tiempo, compañeros y compañeras, ahora es el tiempo de construir la victoria. Esta casa, este lugar, tiene nuestro compromiso irrenunciablede ser llenado de vida, militancia y política.” (H.I.J.O.S., 2011)

En sintonía con esta interpretación del proceso político, es que podemos encontrar numerosas alusiones a Néstor Kirchner a lo largo del discurso de inauguración, mencionado como aquél que dio inicio al ciclo de desarticulación de la "impunidad" en mayo del 2003; como un "militante” y un “compañero":

“Ahí está el legado de ese gran militante que fue Néstor Kirchner, ese compañero que fue Presidente y que con sus convicciones militantes abrió un proceso político lleno de esperanza, que no debe detenerse.” (H.I.J.O.S., 2011)

También, un “compañero” que es capaz de sentir y de emocionarse como las/os “hijxs”, de compartir una causa y comprometerse con lo mismo:

"Nuestra organización, por su ubicación geográfica en ese día, fue testigo de la cara de emoción de Néstor cuando abrió las puertas de este lugar. Era la de un militante haciendo Justicia, la de un militante que como presidente no dejaba sus convicciones atrás.” (H.I.J.O.S., 2011)

Tal como plantea Bolivar (2006) los “discursos emocionales”14 permiten delimitar espacios y también distancias, cercanías y lejanías. La "emoción” que recuperan las/os "hijxs”, reflejaría un sentir compartido ante ese evento político, reforzando la idea de un vínculo con Kirchner que permite entender por qué forman parte del mismo espacio político, donde la afinidad ideológica y política va a la par de una afinidad emocional. En este sentido, se puede rastraer también en los diferentes discursos cómo se va configurando una "lealtad afectiva ${ }^{15}$ " (Jasper, 2013) hacia los dirigentes del kirchnerismo.

En este discurso del año 2011, se recuperan varios elementos presentes en una carta abierta publicada unos meses antes (en octubre del 2010) por un conjunto de hijas/os (firmada por militantes y no militantes de H.I.J.O.S.), luego del repentino fallecimiento de Néstor Kirchner, donde expresaban su dolor a la vez que realizaban una suerte de balance político del ciclo iniciado con su gobierno en mayo del 2003:

“A partir de la asunción de Néstor Kirchner, nuestra historia individual y la historia colectiva de nuestra Patria comenzaron a cambiar. Vimos cómo aquello que considerábamos imposible empezaba a ser real. Festejamos la anulación de las leyes de impunidad. Participamos de la reapertura de los ex CCD y su transformación en Espacios de la Memoria para nuestro pueblo. (...) Pero -por sobre todas las cosasparticipamos y estamos orgullosos de este proceso de transformación del Estado que desde aquel 25 de mayo de 2003 tiene como unos de sus objetivos principales la construcción de un país justo, libre, 
soberano y emancipador, tal como lo soñaron nuestros viejos.” (HIJXS, 2010)

Aquí también, en el reconocimiento del ex Presidente, se entremezclan valoraciones políticas y emotivas, movilizando sentimientos de “orgullo”, agradecimiento, llegando incluso a equiparar la figura de Kirchner con la de un integrante más de su familia, un "padre” o un "tío”:

"Nosotros lo sentimos parte viva de esta familia. Se nos va un padre para muchos de los que no lo tuvimos, se nos fue un tío para otros tantos. Pero, por sobre todo, se nos fue uno de los más brillantes dirigentes políticos que tuvo nuestro país en la historia.” (HIJXS, 2010)

Así como en el fragmento anterior las/os "hijxs” dan cuenta de un proceso político que iba en línea con los “soñaron -sus- viejos”, en este último resurge el componente familístico, evidenciando una importante carga sentimental asociada a su lectura política. Esta figura también se reitera en las entrevistas, utilizando la metáfora del parentesco para expresar una sensación de “orfandad” compartida por las/os “hijxs” ante la muerte de Kirchner y la necesidad "humana y política” que sintieron en ese contexto de expresar públicamente su apoyo a Cristina Fernández de Kirchner (su “madre”, viuda) ante un posible debilitamiento en la gobernabilidad como consecuencia del fallecimiento del líder del partido gobernante:

"Hoy la compañera Cristina necesita de todos y cada uno de nosotros, necesita que seamos cada vez más. Este proceso político que conduce nuestra Presidenta se sustenta y profundiza yendo para adelante. Este tiempo requiere que cada vez seamos más los comprometidos.” (H.I.J.O.S., 2011)

\section{Consideraciones finales}

A lo largo de este trabajo nos hemos aproximado a los sentidos, sentimientos y emociones que preceden, se producen y re-elaboran entre las/os militantes de H.I.J.O.S. Capital a partir de la participación en un espacio de memoria, manifestados en sus discursos.

A la par que la participación y el compromiso de las/os “hijxs” con el Espacio ExESMA se fue incrementando, fueron configurándose procesos de resignificación del lugar, apropiándose del mismo y convirtiéndolo en un espacio donde inscribir su militancia. Este proceso se evidencia, a su vez, en el la transformación de las emociones de "trauma” que primaban frente a los sitios que habían funcionado como CCD, a emociones de "resistencia”, lo cual fue posible - al mismo tiempo que habilitó - una serie de transformaciones al interior de la organización, en sus posicionamientos políticos y particularmente, en su vinculación con el Estado. En este sentido, coincidimos con Bayard De Volo al considerar que "La acción colectiva es generada y genera emociones, emociones como causa y resultado de la participación. Sin embargo, en lugar de dos procesos separados, se alimentan mutuamente” (2006:471 - traducción propia).

De acuerdo con los discursos analizados, es posible identificar una evocación recurrente a las emociones; en línea con lo planteado por Bolívar (2006), la evocación de determinadas emociones aparenta ser una estrategia discursiva y política utilizada por los actores, a diferencia de otros casos estudiados, donde los colectivos implementan estrategias de trabajo emocional orientadas más bien a suprimir la manifestación de emociones, intentando de esta manera transmitir "racionalidad”, comprendido como un atributo de mayor validez en determinados contextos políticos (Whittier, 2001, Poma y Gravante, 2018a).

Por último, recuperando la pregunta sobre la vinculación entre las/os hijxs y el Estado, a diferencia de la mayoría de los casos que han ocupado a las/os investigadores de la protesta en los últimos años, donde se muestra que las emociones de los activistas y movimientos que surgen entre/a partir del vínculo con el Estado suelen ser emociones de "subversivas", tendientes a socavar la legitimidad de las estructuras y/o grupos de poder, desafiando en este sentido también las “reglas del sentir” dominantes (Flam, 2005; Poma y Gravante, 2018a, 2019), en nuestro caso, la orientación fue contraria. Las/os hijxs a lo largo del período estudiado, fueron transformando sus emociones dirigidas a ciertos dirigentes políticos y el Estado, avanzando en la consolidación de una "lealtad afectiva" hacia los presidentes kirchneristas, al mismo tiempo que comenzaba a crearse una 
identificación con lo estatal, del cual pasaron a sentirse parte.

En el caso de las/os "hijxs", como se puede ver con otras organizaciones de "afectados directos" por la represión estatal en Argentina, la vinculación con el Estado a lo largo de los últimos ciclos políticos hasta diciembre del 2015 revela un efecto paradojal, constituyéndose en un primer momento como el responsable de los sentimientos de dolor, injusticia e impunidad que motivan la organización política, pasando a ser ,en esta última etapa, el garante de la "victoria" de esa lucha del MDH que se enlaza con la de la militancia revolucionaria de los sesenta y setenta, permitiendo por ejemplo, transformar los lugares donde se ejerció la violencia estatal en espacios de "memoria viva”, “celebración” y "esperanza”.

La reflexión propuesta en este trabajo comprende una aproximación a la temática, que deja abiertos numerosos interrogantes y dimensiones a explorar, que no pudieron abordarse en este artículo pero esperamos profundizar a futuro, entre ellos: explorar qué formas de trabajo emocional se configuran entre las organizaciones del MDH, qué similitudes y diferencias presentan entre ellas; qué sentidos y emociones se producen y ponen en juego en su relación con el Estado y las autoridades a través de los distintos ciclos políticos; como también, profundizar el análisis de la dimensiones emocional para comprender la permanencia de la organización H.I.J.O.S. a través de los años, teniendo en cuenta sus fracturas, afiliaciones y desafiliaciones de integrantes, entre otros.

\title{
Notas
}

\begin{abstract}
${ }^{1}$ Se parte de una noción de generación que se distancia de la idea de "cohorte” definida en términos biológicos/etarios, entendiéndola como una categoría relacional y producida sociohistóricamente, la cual reúne a un conjunto de sujetos que han compartido un momento histórico de socialización, a la vez que ponen en juego criterios de identificación comunes (Vommaro, 2015). Así como el conjunto de militantes que conforma esta generación del MDH no se agota en aquellos que poseen una filiación directa con las víctimas, tampoco existe una restricción en términos etarios, participando mayormente militantes nacidos en las décadas de 1970 y principios de 1980 , pero conteniendo una amplia heterogeneidad etaria.
\end{abstract}

${ }^{2}$ El "movimiento de derechos humanos" es una categoría nativa utilizada por los actores que lo conforman (y luego adoptada por la sociedad política), que refiere a un conjunto heterogéneo de organizaciones y activistas que llevan adelante acciones públicas y demandas hacia el Estado por el reconocimiento de las violaciones a los derechos humanos ocurridas durante la última dictadura militar. El mismo se conforma por dos grandes grupos de organizaciones: por un lado, los "afectados" directamente por la represión (organizaciones de familiares, madres, abuelas, ex detenidos y desaparecidos e hijos) y por otro lado, los "no afectados" (entre las principales organizaciones: CELS, APDH, LADH, SERPAJ, MEDH y MJDH). (Jelin, 2017)

${ }^{3}$ El término "recuperación” para hacer referencia al proceso de desalojo del predio donde funcionó el Ex CCT- ESMA y la creación de un espacio para la memoria corresponde a una categoría utilizada por las organizaciones de derechos humanos y luego tomada por el Estado, empleándose en discursos oficiales y en la folletería oficial de la SDH durante las gestiones kirchneristas. Para ver más sobre los usos y sentidos de la categoría, ver Croccia et al. (2008), Feld (2011) y D’Ottavio (2016).

\footnotetext{
${ }^{4}$ De acuerdo a la Ley Nacional No 26.691 (2011) se declaran Sitios de Memoria del Terrorismo de Estado "a los lugares que funcionaron como CCD, tortura y exterminio o donde sucedieron hechos emblemáticos del accionar de la represión ilegal desarrollada durante el terrorismo de Estado ejercido en el país hasta el 10 de diciembre de 1983”. Por otra parte, los Espacios para la Memoria son dependencias que pertenecían a las fuerzas armadas y de seguridad, tanto federales como provinciales, que fueron desafectados de su uso militar o policial y destinados a la trasmisión de la memoria, la educación y la promoción de los derechos humanos (Said, 2015). A pesar de esta distinción, en algunos casos la folletería oficial de la SDH menciona a este conjunto de lugares como "Espacios para la memoria" de forma genérica, conteniendo sus diferentes modalidades.

${ }^{5}$ Siguiendo a Hochschild (1979) se utilizará indistintamente la noción de sentimientos y emociones, aludiendo con ello a manifestaciones del cuerpo (bodily cooperations) ante determinados objetos, imágenes, pensamientos, de las cuales el individuo es consciente, pero que son ante todo productos socioculturales, que responden a determinadas "reglas del sentir", las cuales a su vez pueden ser manejadas por los individuos.

${ }^{6}$ Entendemos por gobiernos kirchneristas a los gobiernos nacionales presididos por Néstor Kirchner (2003-2007) y Cristina Fernández de Kirchner (2007-2015).

${ }^{7}$ El predio ubicado en la Avenida Libertador al 8100, en el barrio de Núñez de la Ciudad Autónoma de Buenos Aires (Argentina) comprendido por 17 hectáreas, desde el año 1924 alojó diversas instituciones educativas de la Armada, luego de que el Concejo Deliberante de la ciudad cediera los terrenos al Ministerio de Marina. Durante la última dictadura cívico-militar argentina (1976-1983) ese espacio funcionó como uno de los principales CCD, tortura y exterminio del país. (Said, 2015)
} 
${ }^{8}$ A pesar de que la agrupación H.I.J.O.S. en Capital Federal tiene una política de “población abierta” (es decir, pueden participar tanto familiares directos de las víctimas como cualquier otra persona con afinidad política) para este trabajo se tomará el testimonio de quienes poseen un vínculo familiar directo con las víctimas, ya que explorar la importancia que puede tener ese lazo de parentesco en la actividad militante constituye uno de los objetivos de análisis.

${ }^{9}$ Fuente: Página web del Espacio ExESMA: http://www.espaciomemoria.gov.ar/espaciohoy.php Consultado 11-04-2018.

${ }^{10}$ El documento fue leído por dos integrantes de H.I.J.O.S. La Plata, nacidos en la ESMA, (María Isabel Prigione y Emiliano Hueravillo) pero acordado por todas las regionales que conformaban la Red Nacional, de acuerdo al testimonio de los entrevistados.

${ }^{11}$ La Ley de Punto Final (n 23.492 del año 1986) establecía la caducidad de la acción penal contra los imputados como autores responsables de los delitos asociados a la instauración de formas violentas de acción política hasta el 10 de octubre de 1983 (fecha en que finalizaba la dictadura militar argentina). Su ley complementaria, la de “Obediencia Debida” (nº 23.521 del año 1987) establecía que no serían punibles los delitos cometidos durante la dictadura militar por miembros de las Fuerzas Armadas con grado inferior a coronel, basándose en la presunción de que los subordinados se limitan a obedecer órdenes de sus superiores. Mientras que estas dos leyes fueron sancionadas durante la presidencia de Raúl Alfonsín, los llamados “Indultos” fueron un conjunto de decretos sancionados por el entonces presidente de la Nación Carlos Menem, entre los años 1989 y 1990, que dictaban la extinción de responsabilidad penal a civiles y militares que habían sido condenados por crímenes cometidos durante la dictadura militar (incluyendo numerosos casos de militares que no habían sido alcanzados por las leyes anteriores de Obediencia debida y Punto Final). Las leyes de obediencia debida y punto final fueron anuladas en el año 2003 y declaradas inconstitucionales en el año 2005, lo mismo que los indultos, en el año 2006.

${ }^{12}$ Sobre las leyes reparatorias de contenido económico y la interpretación de algunas/os “hijxs”, ver Goyochea, Pérez y Surraco (2011).

${ }^{13}$ De acuerdo a los testimonios y la consulta de fuentes periodísticas, militantes de H.I.J.O.S. han ocupado diversos puestos de trabajo y gestión en el Espacio ExESMA: en el equipo de Guías, el ANM, programas del Ministerio de Educación, el ECuNHi en la SDH, cumpliendo funciones también en el órgano ejecutivo del Ente como representantes tanto del P.E.N. como del Directorio.

\footnotetext{
${ }^{14}$ La noción de "discursos emocionales" parte de una noción del discurso comprendida como producción verbal y también práctica social, que pretende producir sentido y generar un efecto determinado. Lo "emocional" se manifiesta tanto en el contenido del discurso, a partir de la utilización de palabras que referencien sentimientos, recursos retóricos, como también los efectos de clasificación de situaciones y acciones. (Bolivar, 2006)

${ }^{15}$ Se entiende por "lealtad afectiva” a los sentimientos relativamente estables, que pueden ser positivos o negativos, en relación a otros o sobre objetos, como el amor, la confianza, el respeto o sus opuestos. (Jasper, 2013). Aunque Jasper recupera mayormente esta acepción cuando se refiere a los compromisos afectivos entre los miembros de un colectivo y su rechazo hacia un objeto o figura externa, en este caso se toma en su sentido más vinculado al tipo de orientación emocional que generan los "liderazgos carismáticos" en términos de Weber.
}

\section{Bibliografía}

Adams, J. (2003). TheBitterEnd: Emotions at a Movement’sConclusion.SociologicalInquiry, 73, 84-113.

Alonso, L. (2016). ¿Por qué seguir reflexionando a 20 años de HIJOS?. Cuadernos de Aletheia, (2), 2-7. Recuperado de:http://sedici.unlp.edu.ar/handle/10915/59510.

(2009) Memorias sociales y Estado en Santa Fe, Argentina, 2003-2008. Revista Política y Cultura, (31) 27-47.

Andriotti Romanin, E. S. (2015). Actores, Estado y políticas públicas reparatorias en relación al terrorismo de Estado en Argentina (2003-2007). Sudamérica: Revista de Ciencias Sociales, 1(4), 136-155. Recuperado de: https://fh.mdp.edu.ar/revistas/index.php/sudamerica/article/view/1555.

(2014). Cooptación, oportunidades políticas y sentimientos. La Asociación Madres de Plaza de Mayo de Argentina y el gobierno de Néstor Kirchner. Polis, Revista Latinoamericana, (39). 13(39), 229-247. https:/ /dx.doi.org/10.4067/S0718-65682014000300011

(2012). De la confrontación a la cooperación. Los cambios en las estrategias y marcos interpretativos del Movimiento de derechos humanos de Argentina frente al "Kirchnerismo” (2003-2011). En: Tejerina, P. y Perugorria, I. (eds.),Global Movements, NationalGrievances. Mobilizingfor iReal Democracy ì and Social Justice(pp. 54-79). Bilbao, España: Universidad del País Vasco. 
Bayard De Volo, L. (2006). The Dynamics of Emotion and Activism: Grief, Gender,and CollectiveIdentity in Revolutionary Nicaragua. Mobilization, 11(4), 461-474.

Bolivar R., I. (2006). Discursos emocionales y experiencias de la poliitica. Las FARCy las AUC en los procesos de negociacioìn del conflicto (1998- 2005).Bogotaì, Colombia: Ediciones Uniandes.

Bonaldi, P. (2006). Hijos de desaparecidos. Entre la construcción de la política y la construcción de la memoria. En: Jelin, E. y Sempol, D. (comps.) El pasado en el futuro: los movimientos juveniles (pp.143-184). Buenos Aires, Argentina: Siglo XXI.

Croccia, M., Guglielmucci, A. y Mendiazabal, M. E. (2008). Patrimonio Hostil: Reflexiones sobre los proyectos de recuperación de ex Centros Clandestinos de Detención en la Ciudad de Buenos Aires. IX Congreso Argentino de Antropología Social, Posadas: Facultad de Humanidades y Ciencias Sociales - Universidad Nacional de Misiones, Misiones, Argentina. Recuperado de:

Cueto Rúa, S. (2016a). El Surgimiento de la agrupación H.I.J.O.S.. Cuadernos de Aletheia, (2), 8-13.Recuperado de: http://sedici.unlp.edu.ar/handle/10915/59511

(2016b).”Ampliar el círculo de los que recuerdan”. La inscripción de la Comisión Provincial por la Memoria en el campo de los derechos humanos y la memoria (1999-2009)(Tesis de Doctorado).Universidad Nacional de La Plata, La Plata, Argentina. Recuperado de: http://www.memoria.fahce.unlp.edu.ar/tesis/ te.1313/te.1313.pdf

(2010b). El surgimiento de la agrupación HIJOS-La Plata: La discusión por quienes son las víctimas del terrorismo de Estado. Sociohistórica(27), 137-163.

(2010a). Hijos de víctimas del terrorismo de Estado. Justicia, identidad y memoria en el movimiento de derechos humanos en Argentina, 1995-2008. Historia Critica (40), 122-144. Recuperado de: http:// www.memoria.fahce.unlp.edu.ar/art_revistas/pr.7384/pr.7384.pdf

(2007). Víctimas y revolucionarios. Question, 1 (13), 1-8. Recuperado de: http://hdl.handle.net/10915/ 30378.

D’ottavio, A. (2016). Apuntes sobre conservación material de sitios de memoria emplazados en CCDTyE de la Ciudad de Buenos Aires: desafíos y tensiones. Cuadernos del IDES, (32), 57-76.

Da Silva Catela, L. (2014). “Lo que merece ser recordado...”. Conflictos y tensiones en torno a los proyectos públicos sobre los usos del pasado en los sitios de memoria. Clepsidra. Revista Interdisciplinaria de Estudios sobre Memoria, 1(2), 28-47.

Della Porta, D. (1995). Social Movements, Political Violence and the State: a comparative analysis of Italy and Germany. Cambridge, UnitedStates: Cambridge UniversityPress

Di Marco, L. (2012).La Cámpora: Historia secreta de los herederos de Néstor y Cristina Kirchner. Buenos Aires, Argentina: Sudamericana.

Feld, C. (2017). Preservar, recuperar, ocupar. Controversias memoriales en torno a la ex-esma(1998-2013). Rev. Colomb. Soc., 40(1), 101-131.

(2011). La memoria en su territorio. En: Fleury, B. y Walter, J. (comps.),Memorias de la piedra. Ensayos en torno a lugares de detención y masacre. Buenos Aires, Argentina: Ejercitar la memoria editores.

Flam, H.(2005). Emotion's map: a research agenda. En: H. Flam y D. King (eds.), Emotions and Social Movement. Londres/Nueva York, England/ United States: Routledge 
Gamson, W., \& Meyer, D. (1996). Framing political opportunity. In D. McAdam, J. McCarthy, \& M. Zald (Eds.), Comparative Perspectives on Social Movements: Political Opportunities, Mobilizing Structures, and Cultural Framings (pp. 275-290). Cambridge: Cambridge University Press. doi:10.1017/CBO9780511803987.014

Gasulla, L. (2012). El negocio de los derechos humanos. Buenos Aires, Argentina: Sudamericana.

Goffman, E. (2006).FrameAnalysis. Madrid, España: Centro de Investigaciones Sociológicas.

Goyochea, Á., Perez, M. E. y Surraco, L. (2011) Definiciones del universo de víctimas desde el Estado postgenocida: la invisibilidad de los hijos de desaparecidos y asesinados como sujeto de derecho. Recuperado de: http://www.genocidescholars.org/sites/default/files/document\%09\%5Bcurrent-page:1\%5D/documents/ IAGS\%202011\%20GOYOCHEA,\%20SURRACO,\%20PEREZ.pdf

Guglielmucci, A. (2011) El proceso social de consagracioìn de la memoria sobre el terrorismo de Estado como poliiticapuiblica estatal de derechos humanos en Argentina (Tesis doctoral). Universidad de Buenos Aires, Buenos Aires, Argentina. Recuperado de: http://repositorio.filo.uba.ar/handle/filodigital/1705

Hochschild, A. R. (1983). The Managed Heart: the commercialization of human feeling. Berkeley, US: University of California Press.

(1979).Emotion work, feeling rules, and social structure. American Journal of Sociology, 85, 551-575.

Jasper, J. (2013). Las emociones y los movimientos sociales: veinte años de teoría e investigación. Revista Latinoamericana de Estudios sobre Cuerpos, Emociones y Sociedad, 4 (10), 48?68.

(2012). ¿De la estructura a la acción? La teoría de los movimientos sociales después de los grandes paradigmas. Sociológica, 27 (75), 7-48.

Jelin, E. (2017). Certezas, incertidumbres y búsquedas. El movimiento de derechos humanos y la construcción democrática en la Argentina. En: La lucha por el pasado: cómo construimos la memoria social (pp. 85150). Buenos Aires, Argentina: Siglo XXI Editores.

(2007). Víctimas, familiares y ciudadanos/as: las luchas por la legitimidad de la palabra. Cadernospagu (29), 37-60.

(2003).La escala de acción de los movimientos sociales. En: Jelin, E. (Comp.) Más allá de la nación: las escalas múltiples de los movimientos sociales(pp.25-60).Buenos Aires, Argentina: Libros de Zorzal.

McAdam, D., McCarthy, J., \& Zald, M. (1999). Oportunidades, estructuras de movilización y procesos enmarcadores: hacia una perspectiva sintética y comparada de los movimientos sociales. Movimientos sociales: perspectivas comparadas, 21-46.

Messina, L. (2016). Reflexiones sobre la articulación Estado-sociedad civil en las políticas de la memoria en Argentina. Revista Memóriaem Rede, 8(15), 109-136.

(2015).Políticas de la memoria y construcción de memoria social: acontecimientos, actores y marcas de lugar El caso del ex centro clandestino de detención” Olimpo” (Tesis doctoral). Universidad Nacional de Buenos Aires, Buenos Aires, Argentina. Recuperada de: http://repositorio.filo.uba.ar/handle/filodigital/1647

Olson, M. (1965). TheLogic of CollectiveAction: PublicGoods and theTheory of Groups. Cambridge Mass.: Harvard UniversityPress.

Otero Bahamoìn, S. (2006). Emociones y movimientos sociales. Colombia Internacional, (63), 174 - 187. 
Poma, A. y Gravante, T. (2019). Emociones, trauma cultural y movilizacioìn social: el movimiento por las viìctimas de Ayotzinapa en Meìxico. Perfiles Latinoamericanos, 27 (53). DOI: 10.18504/pl2753-007-2019.

(2018a). Manejo emocional y accioìn colectiva: las emociones en la arena de la lucha poliìtica. Estudio Socioloìgico, 36 (108), 593-616. DOI: 10.24201/es.2018v36n108.1612.

(2018b). Emociones, identidad colectiva y estrategias en los conflictos socio-ambientales. Andamios. Revista de Investigación Social, 15 (36), 287-309. DOI 10.29092/uacm.v15i36.611

(2015). Las emociones como arena de la lucha política. Incorporando la dimensión emocional al estudio de la protesta y los movimientos sociales. Ciudadanía Activa, Revista Especializada en Estudios sobre la Sociedad Civil, 3(4), 17-44.

Romanos, E. (2014). Emotions, Moral Batteries and High-Risk Activism: Understanding the Emotional Practices of the Spanish Anarchists under Franco’s Dictatorship. Contemporary European History, 23(4), 545-564.

(2011). Emociones, identidad y represión: el activismoanarquista durante el franquismo. Reis, (134), 87-106.

Said, J. (coord.) (2015).Espacios de memoria en la Argentina. Buenos Aires: Ministerio de Justicia y Derechos Humanos de la Nación. Secretaría de Derechos Humanos.

Svampa, M. (2018). Conferencia: Los movimientos sociales en las experiencias de gobierno: ¿Cooptación o alianzas para el cambio? (Mimeo), $8^{\circ}$ Conferencia Latinoamericana y Caribeña de Ciencias Sociales, Facultad de Ciencias Sociales, Universidad Nacional de Buenos Aires, Ciudad de Buenos Aires, Argentina, 21 de noviembre.

Vecchioli, V. (2005) La nación como familia. Metáforas políticas en el movimiento argentino por los derechos humanos. Cultura y política en etnografías sobre la Argentina, 241-270.

(2001) Poliìticas de la memoria y formas de clasificación social. ¿Quieìnes son las viìctimas del terrorismo de Estado ì en la Argentina. En: Groppo, B. Y Flier, P.(comps.),La imposibilidad del olvido (pp.83-102). La Plata, Argentina: Ediciones Al

Vezzetti, H. (2009).Sobre la violencia revolucionaria. Buenos Aires,Argentina: Siglo XXI.

Vommaro, P. (2015). Juventudes y políticas en la Argentina y en América Latina. Tendencias, conflictos y desafíos. Buenos Aires,Argentina: Grupo Editor Universitario.

Whittier, N. (2001). EmotionalStrategies: TheCollectiveReconstruction and Display of Oppositional Emotions in the Movement against Child Sexual Abuse. En: Goodwin, J.,Jasper, J. y Polletta, F. [eds.],PassionatePolitics: Emotions and Social Movements,Chicago,US: University of Chicago Press.

Wood, E. (2001). The Emotional Benefits of Insurgency in El Salvador. En: Goodwin, J., Jasper, J. y Polletta, F. [eds.], Passionate Politics: Emotions and Social Movements, Chicago, US: University of Chicago Press.

\section{Documentos, discursos y declaraciones públicas}

H.I.J.O.S. (2012). Comunicado “““Genocida Videla: nuestra única venganza es ser felices”. Disponible en: http:// www.agenciapacourondo.com.ar/mas-informacion/hijos-genocida-videla-nuestra-unica-venganza-es-ser-felices (consultado 25-04-2019)

(2011) Documento leído 27-06-2011 en la Casa de la Militancia (Espacio ExESMA), CABA. Disponible en: https://www.cta.org.ar/IMG/pdf/discurso_27_de_junio_inauguracion_casa_hijos.pdf (consultado 2504-2018) 
(2004) Documento leído 24-03-2004 en la Ex ESMA, CABA. Disponible en: http://argentina.indymedia.org/ news/2004/03/185382.php (consultado 25-04-2018)

HIJXS (2010) Carta abierta de los hijos de desaparecidos (firmada por algunos miembros de H.I..J.O.S.). En: Página 12, 29 de octubre de 2010. Disponible en: https://www.pagina12.com.ar/diario/elpais/1-1559082010-10-29.html (consultado 25-04-2018)

Kirchner, N (2004) Palabras del Presidente de la Nación, Dr. Néstor Kirchner, en el acto de firma del convenio de la creación del Museo de la Memoria y para la promoción y defensa de los Derechos Humanos. Disponible en: https://www.casarosada.gob.ar/informacion/archivo/24549-blank-79665064 (consultado 25-04-2018)

Militante de H.I.J.O.S. (2013). Entrevista a Paula Maroni. En: Serre, E., Programa de Investigación Eduardo Luis Duhalde. Recuperada de: http://papelesynotasddhh.blogspot.com/p/paula-maroni.html (consultado 1-05-2019)

Militante de H.I.J.O.S. (2015). Entrevista a Carlos Pisoni; “Todos somos hijos de la dictadura, porque todos vivimos las consecuencias del terrorismo de Estado”, 21 de mayo de 2015. En: Web del Espacio Ex ESMA. Disponible en: www.espaciomemoria.ar/opinion.php?op_ID=84\&barra=opinion (consultado 1-03-2018)

\section{Notas periodísticas}

Etchenique, M. B. (2013). Insólito argumento para defender los asados K en la ESMA: “Acá no se mató a nadie”, Clarin Online, 2 de septiembre de 2013. Disponible en: https:/www.clarin.com/politica/insolito-argumento-defender-esma-aca_0_SJfEIcNov7l.html (consultado 1-05-2019)

S/A (2013). Nora Cortiñas, “indignada” con el asado en la ESMA: "No se puede banalizar lo que vivimos". Infobae, 3 de septiembre de 2013. Disponible en: https:/www.infobae.com/2013/09/03/1506164-nora-cortinas-indignada-el-asado-la-esma-no-se-puede-banalizar-lo-que-vivimos/ (consultado 1-05-2019)

(2013) La simbología de “los asados” en la ESMA, según sobrevivientes. Rio Negro, 3 de enero de 2013. Disponible en: https:/www.rionegro.com.ar/en-foco-la-simbologia-de-los-asados-en-la-esma-segun-sobrevivientes-GQRN_1041951/(consultado 1-05-2019) 